\title{
Urban-Design Process with Snow and Wind Simulations: A Study on the Kitami City Hall
}

\author{
Norihiro Watanabe ${ }^{1}$, Tsuyoshi Setoguchi ${ }^{1}$, Shota Yokoyama ${ }^{1}$, Zhiming Guo ${ }^{1}$ and Takuya Tsutsumi ${ }^{2}$ \\ 1. Graduate School of Engineering, Hokkaido University, Sapporo 060-8628, Japan \\ 2. Northern Regional Building Research Institute, Hokkaido Research Organization, Asahikawa 078-8801, Japan
}

\begin{abstract}
Regional climatic conditions should be considered while designing urban development plans, with special attention to the impact of snowfall on public spaces in cities with harsh winters. The Kitami-city-hall-renewal project in Hokkaido, Japan was studied as an environmental assessment of snow drifting. Assessments of the two site plans proposed during the architectural planning process (A-type and B-type) were conducted in terms of the following three items: (1) The two site plans indicate snow-drifting problems around the main entrance; (2) More number of local snowdrifts on the main-street sidewalks were suggested in the B-type design; (3) Less number of snowdrifts in the parking area beside the railroad were indicated in the A-type design. These results were reflected in the architectural planning process. On the basis of this study, a desirable design process incorporating environmental assessments has been identified for cities with harsh winters.
\end{abstract}

Key words: Winter cities, snow simulations, wind tunnel, urban design, environmental assessments.

\section{Introduction}

Consideration of regional climatic conditions is one of the most sustainable approaches to urban and architectural design. Historically, the same urban-design approaches have been applied for different regions without considering their individual climatic conditions. In cities that suffer from heavy snow and cold wind (winter cities), a different urban-design approach than that for warm cities should be adopted [1, 2]. Recently, the relation between urban design and climatic impacts has attracted academic interest in subjects such as pedestrian comfort, urban heat-island reduction, and air ventilation in urban areas [3]. Most recent studies have targeted warm regions, whereas only few studies have reported on snow environments in cold regions. It is important to clarify the application of urban-design principles in reducing the negative impacts of climate, especially in winter cities.

Corresponding author: Norihiro Watanabe, Dr student, research field: urban design for winter cities. E-mail: norihiro-watanabe@eis.hokudai.ac.jp.
Snow is one of the most important impact points to be considered for urban design in winter cities. These cities spend a lot of money in overcoming their snow problems. Desirable urban designs that reduce these climate-induced problems should be developed in winter cities.

Specifically, urban-design approaches should address public-space planning during urban-renewal projects. Good public spaces tend to attract more people, connect different urban functions, and provide pleasant urban life for citizens. Various outdoor activities in public spaces are influenced by their microclimatic environment. Urban-renewal projects offer good opportunities to create favorable public spaces and environments. Design approaches for such projects that incorporate environmental assessments are required for creating outdoor comfort, thereby promoting a symbiotic relation between the people and climate toward the realization of sustainable cities.

Therefore, the purpose of this study is to determine an urban design process with environmental 
assessments for urban-renewal projects in winter cities. The Kitami city-hall in Hokkaido, which is located in northernmost Japan, was chosen as a case study. As a part of the Kitami urban-regeneration master plan, the actual project commenced in 2015 and is being managed by the city of Kitami. The officers in Kitami and the authors studied desirable designs for the new Kitami city-hall, which consider the local climate conditions during winter. Both interior and outdoor planning were considered during general city-hall planning. This study focused on the outdoor-planning period after the interior design had been almost entirely decided. The winter outdoor environments were assessed by snow simulations using a wind tunnel. The assessment results were reflected in the architectural planning. Therefore, the effects of the design approach with environmental assessments have been clarified and a process incorporating environmental assessments was concluded based on the results.

Many prior studies of environmental assessments in building design have exclusively utilized wind-simulation tests. Bosselmann et al. studied downtown San Francisco, California, USA and showed, by simulation using a wind tunnel, that new high-rise developments are causing environmental problems resulting from changes in wind and sunlight conditions [4, 5]. Kim and Macdonald compared San Francisco's wind environments in 1985 and 2013, and showed the effect of controlling urban forms in the wind environment using a wind tunnel [6]. Tomabechi et al. simulated the effect of snow with a wind tunnel [7]. This approach is suitable for determining desirable building design related to snow and wind, but does not consider broader urban-space design. Limited studies have been performed on the environmental influence of snow and wind in simulation tests using wind tunnels for urban design. Setoguchi and Watanabe et al. considered the urban-design process, including snow and wind environmental assessments for winter cities [8-15]. These studies discussed models that were theoretically planned for developing desirable urban designs. The present study conducts snow simulations for planning the actual project (Table 1). On the basis of the analysis of the relation between architectural planning and environmental assessments, this study proposes a desirable planning process that incorporates environmental assessment of winter cities.

\section{Method}

\subsection{Wind-Tunnel Settings}

The snow-simulation-testing methods in this study were based on previous research [14, 15]. Snow-simulation tests were performed using the boundary-layer wind tunnel at the Hokkaido Research Organization (Fig. 1). The wind tunnel is $7 \mathrm{~m}$ long, $1.5 \mathrm{~m}$ wide, and $0.7 \mathrm{~m}$ high. Snowfall was replicated using compressed air to blow model snow from the windward supply nozzle. Model snow was white soil powder with a moisture content of $8.5 \%$, an average diameter of $20 \mu \mathrm{m}$, and an angle of repose of $48^{\circ} \sim 51^{\circ}$. Model snow was incrementally supplied to the wind tunnel at a rate of approximately $480 \mathrm{~g} / \mathrm{min}$; the total amount of model snow was $10 \mathrm{~kg}$ per experiment. The deposition depth of model snow was measured using an LK500 laser manufactured by Keyence. In this study, it took approximately $20 \mathrm{~min}$ for $10 \mathrm{~kg}$ of snow to be deposited.

This is comparable to 7 days of snowfall at $7 \mathrm{~cm}$ per day in a real environment. With $2.9 \mathrm{~min}$ of the

Table 1 Prior studies of snow and wind effects using wind tunnels.

\begin{tabular}{lll}
\hline Simulation & Building design & Urban design \\
\hline For only wind & (Several reports) & Bosselmann et al. (1984) [4, 5], Kim and Macdonald (2015) [6] \\
\hline For wind \& snow & Tomabechi et al. (2012) [7] & $\begin{array}{l}\text { Setoguchi et al. (2003-2012) [8 14]: theoretical models } \\
\text { Watanabe et al. (2016) [15]: theoretical models } \\
\text { This study: actual project }\end{array}$ \\
\hline
\end{tabular}




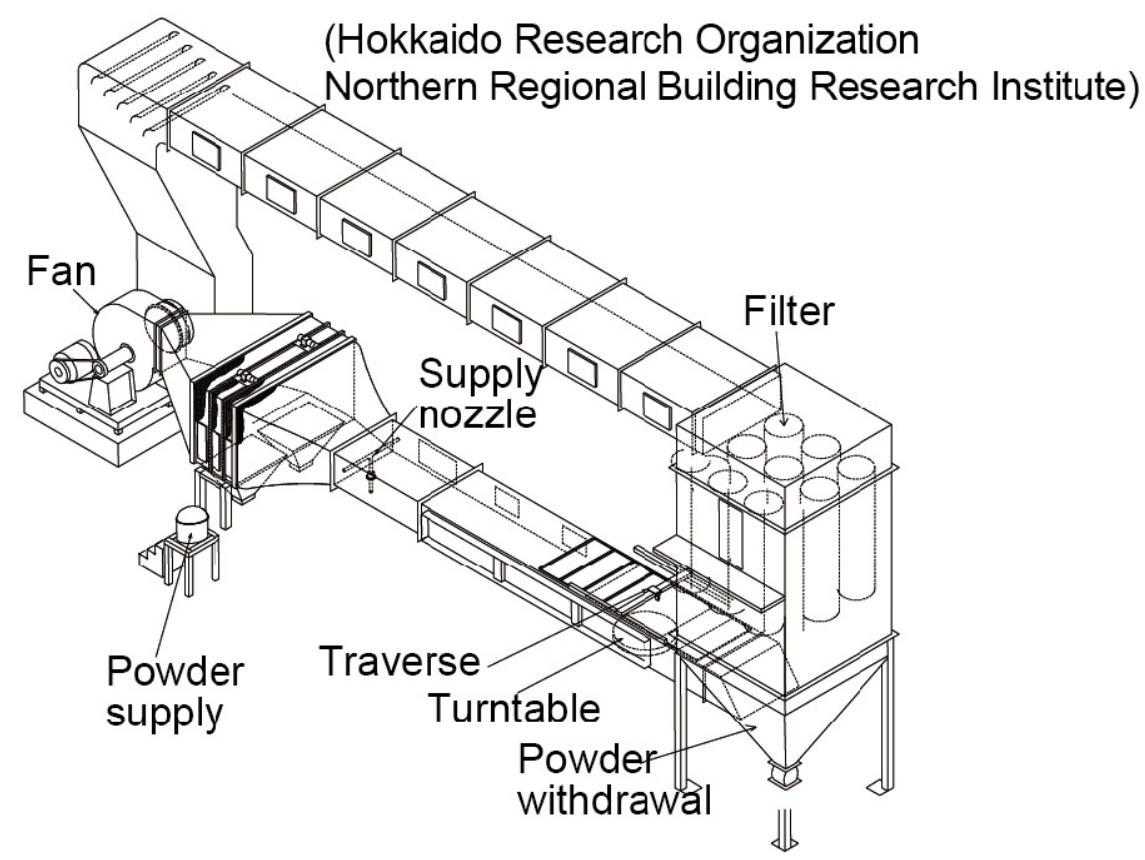

Fig. 1 Wind tunnel used for the snow simulations.

experimental simulation corresponding to one real day, the deposited depth of the model snow was small and the measurements were susceptible to errors. To minimize the potential error, experimental equivalents considered a one-week deposition time $(20.2 \mathrm{~min})$ that resulted in an average model-snow depth of approximately $1 \mathrm{~mm}$. In calculations, one-week-equivalent depth results were divided by seven to determine average snow depths per day. The reproducibility of this snow-simulation method has been reported in previous research [16-18].

Fig. 2 shows the winter-wind data in Kitami, as reported by the Japan Meteorological Agency (2010-2015). The wind conditions between December 2010 and March 2015 were strong with snow blowing from the north $(\mathrm{N})$ and southwest $(\mathrm{SW})$. Average wind velocities from the north and southwest of $2.8 \mathrm{~m} / \mathrm{s}$ and $1.6 \mathrm{~m} / \mathrm{s}$, respectively, were used for the snow simulations in this study.

The wind conditions were simulated using the velocity and turbulence-intensity profiles shown in Fig. 3. The wind speed in the wind tunnel was set equal to the actual average wind speed using equations previously derived by Anno [16]. In Kitami, the vertical wind profile follows an $\alpha=0.27$ power law. Anno developed Eq. (1) to determine the wind speed at some reference height given the threshold-friction speed of the particles. In Eq. (1), $U_{p}$ is the real-phenomenon wind speed at some reference height, $U_{m}$ is the experiment wind-speed value at some reference height, $A_{p}$ and $A_{m}$ are constants, $U^{*}{ }_{t}$ is the real-phenomenon threshold-friction speed of the particles, and $U_{t m}^{*}$ is their experimental threshold-friction-speed value. When activated clay is used as model snow, Eq. (1) is simplified as Eq. (2):

$$
\begin{gathered}
U_{p} / U_{m}=\left(A_{m} \cdot U_{t p}^{*}\right) /\left(A_{p} \cdot U_{t m}^{*}\right) \\
U_{p} / U_{m}=1.375 \cdot U_{t p}^{*} / U_{t m}^{*}
\end{gathered}
$$

\subsection{Models for Snow Simulations}

For the snow-simulation tests, the target building models were manufactured from Styrofoam at a 1:400 scale (Fig. 4). The target area measured $726 \mathrm{~m}$ by $596 \mathrm{~m}$. The scale models measured $1,815 \mathrm{~mm}$ long by $1,490 \mathrm{~mm}$ wide. Required simulation times and results were proportional to the model's 1:400 scale based on the theory of homothetic ratios for model experiments [19]. 


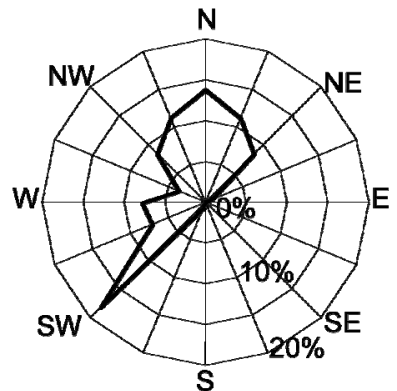

Frequency distribution of the wind direction (\%)

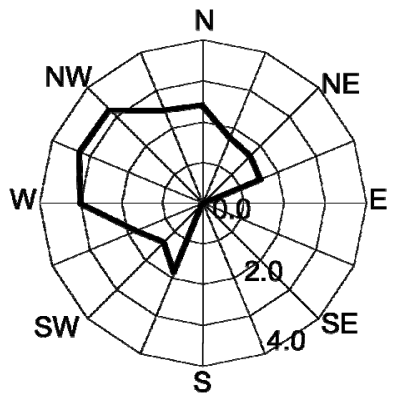

Average wind speed according to the wind direction $(\mathrm{m} / \mathrm{s})$

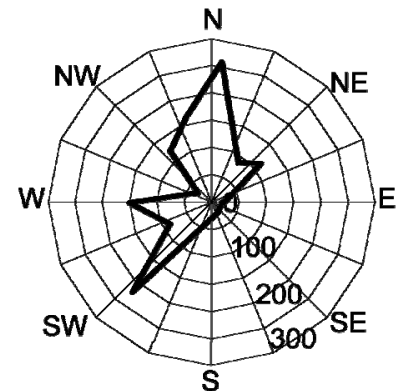

Cumulative snowfall according to the wind direction $(\mathrm{cm})$

Fig. 2 Wind data in Kitami (Dec. 2010-Mar. 2015).
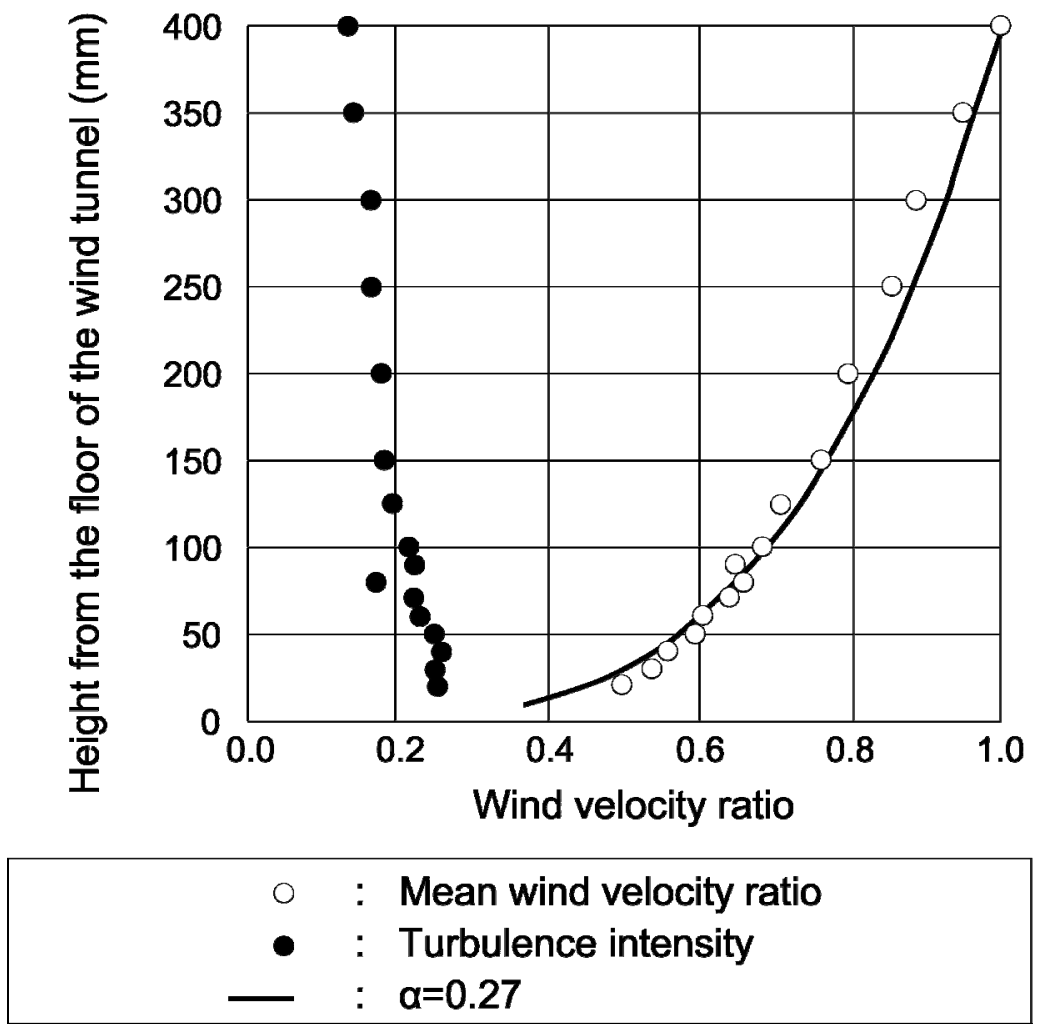

Fig. 3 Wind flow in experiments.

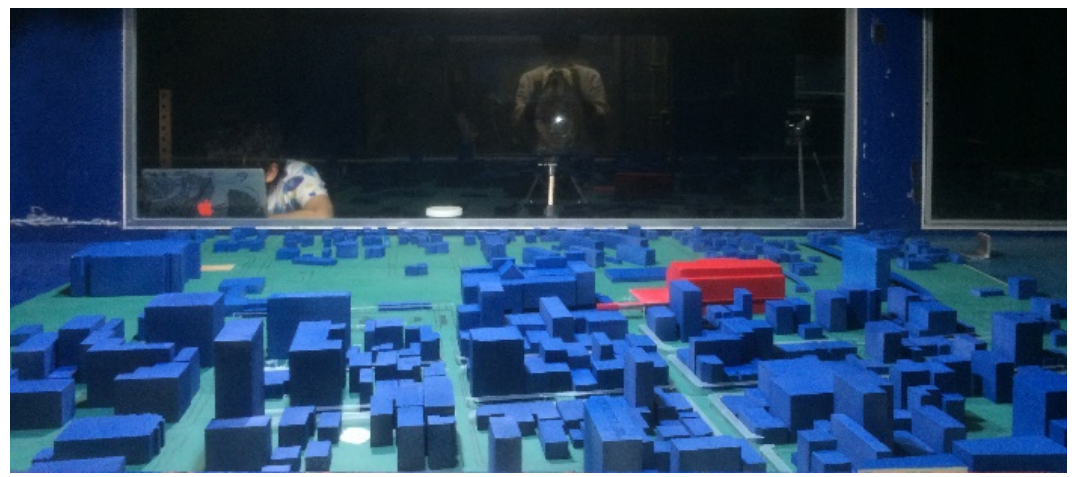

Fig. 4 Model for snow and wind simulations. 


\section{City Hall-Renewal Plan in Kitami}

\subsection{Winter Climate of Kitami City}

Hokkaido is in the northernmost part of Japan, a cold region with heavy snowfall. There are numerous cities and towns suffering from severe snow problems in winter. In Kitami, which is located in the east of Hokkaido (Fig. 5), the snowfall has been increasing yearly (Fig. 6, as reported by the Japan Meteorological Agency). Fig. 7 shows the winter snow accumulation in Kitami, as reported by the Japan Meteorological Agency (2014-2015). The snow cover begins to form at the end of December and remains until the beginning of April for approximately four months. In Kitami, snow can be heavy sometimes over one year, leading to traffic and pedestrian problems. Hence, the new city hall, which will be used by many citizens, should be designed with consideration of snow drift.

\subsection{The Kitami City Hall-Renewal Project}

The planning site of new Kitami city hall is located on the west side of the Kitami station, next to the Machikita-Odori Building (MO bldg.), which is one of the largest commercial buildings in Kitami (Fig. 8).

The Kitami Urban-Regeneration Master Plan started in 2010 and has created two urban-core areas and an urban corridor to connect them. One urban-core

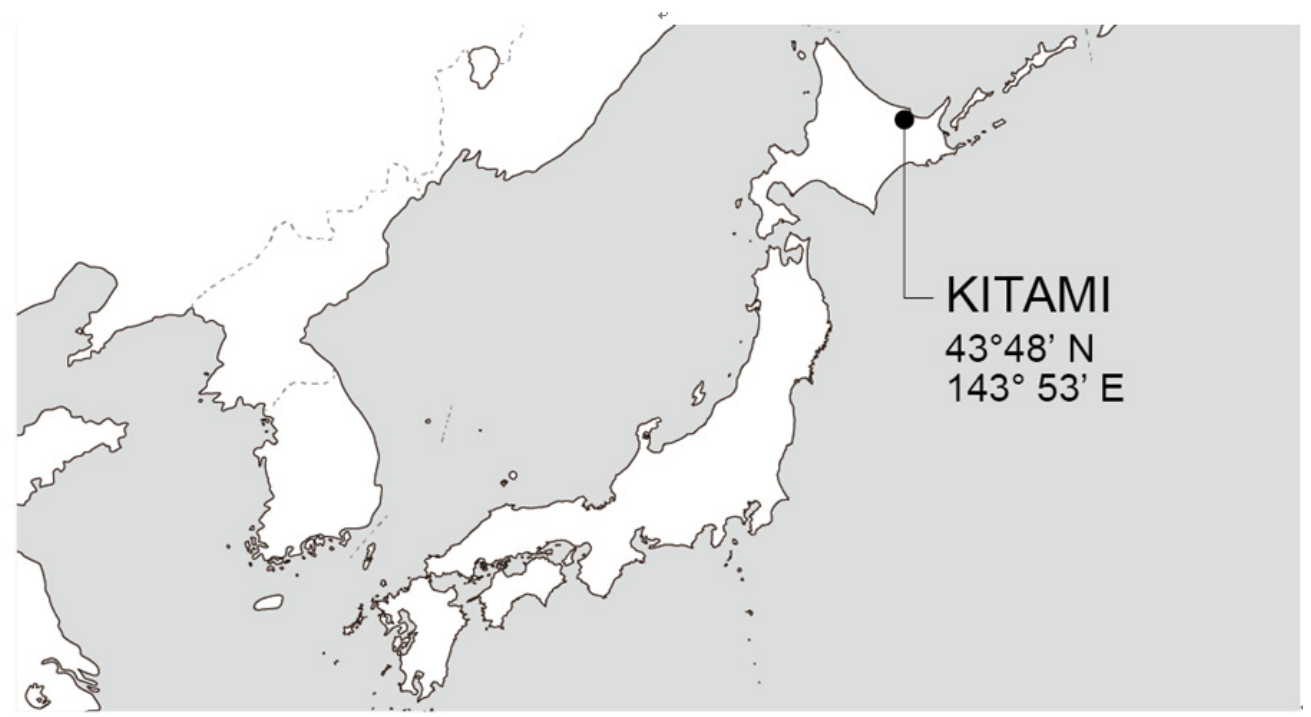

Fig. 5 Location of Kitami.

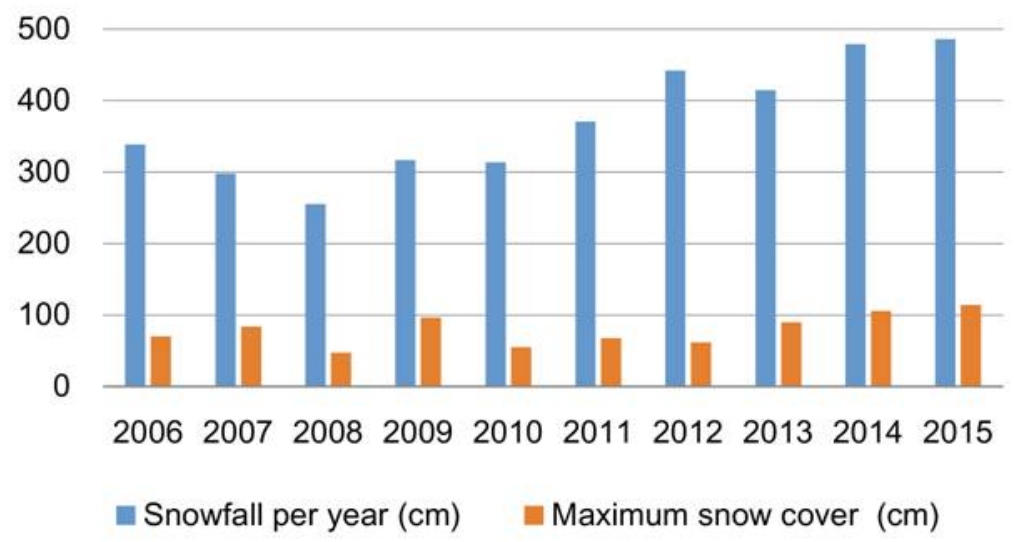

Fig. 6 Snow data for Kitami (2006-2015). 


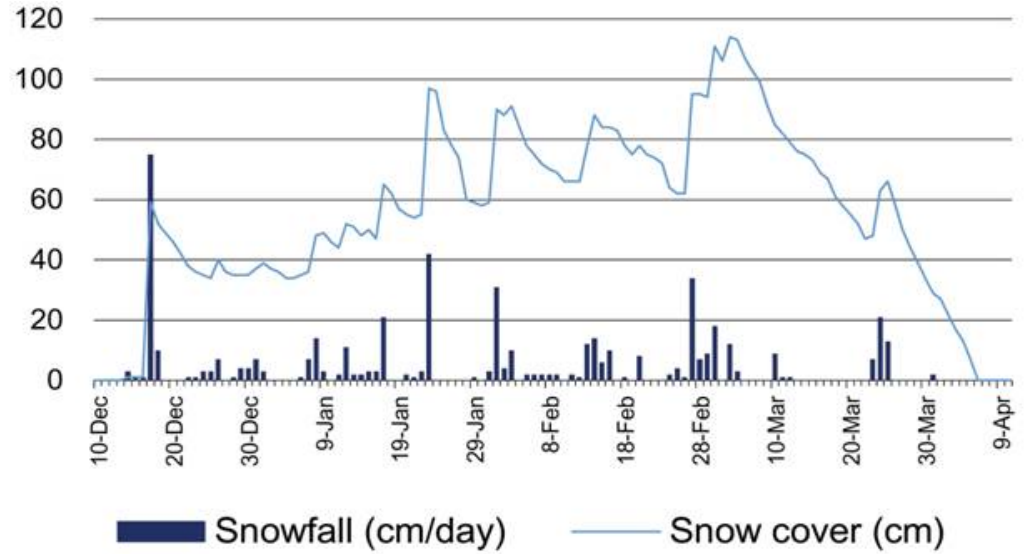

Fig. 7 Snow accumulation in Kitami (2015).

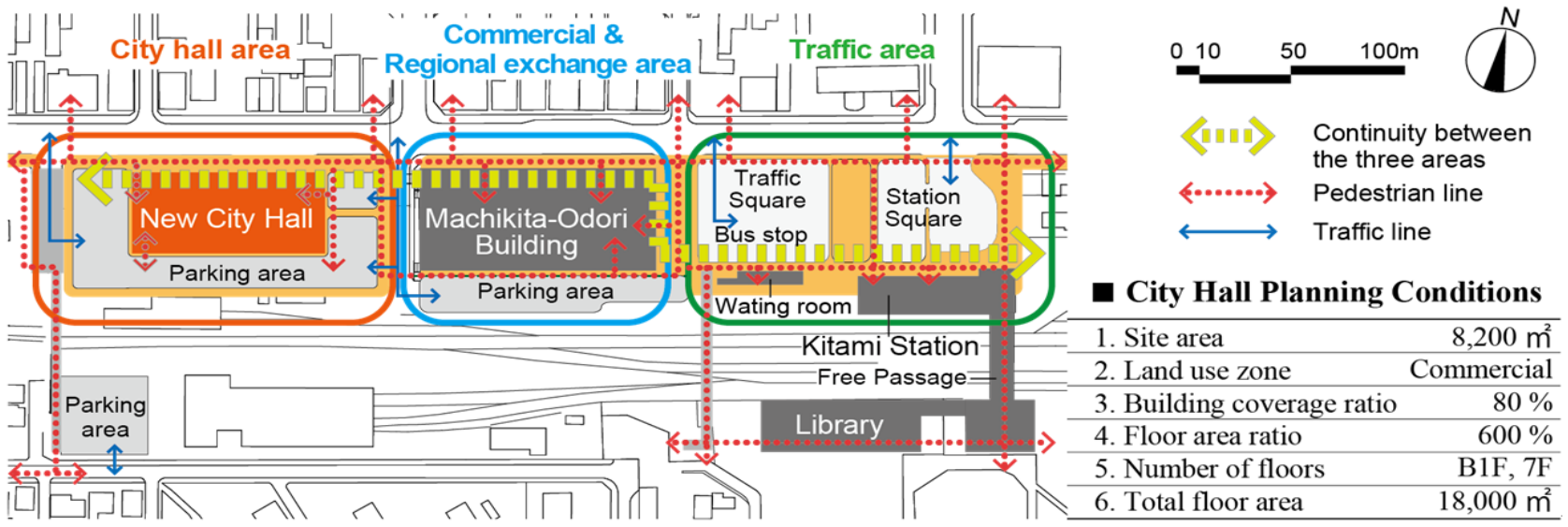

Fig. 8 The urban-core-area plan including the new city hall.

area includes the new Kitami city hall, the MO bldg., and the Kitami station. Urban core-area planning is aimed at combining the city-hall area, the commercial and regional exchange areas (including the MO bldg.), and the traffic area (including Kitami station). In combining these three areas, outdoor pedestrian activities are important to consider. Creating comfortable public-space environments in this core area was one of the requirements of the plan. Since the city-hall-renewal project is the first step of core-area redevelopment, it is expected to act as the guideline for the Kitami urban-regeneration master plan. The conditions of the new city hall plan are shown in Fig. 8.

\section{Planning for the New City Hall}

\subsection{Site Plan}

In the schematic design of the new city hall, site and interior planning were studied based on the following seven requirements:

(1) The service counter $\left(1,500 \mathrm{~m}^{2}\right)$ should be set on the first floor;

(2) Each floor should be over 2,700 $\mathrm{m}^{2}$;

(3) There should be 150 parking lots in total;

(4) A traffic line should be able to connect both the parking areas of the city hall and the MO bldg.;

(5) A common parking area should be located between the new city hall and the MO bldg. with consideration of easy access to both buildings;

(6) A pedestrian walkway should be established to connect the city hall and the MO bldg.

(7) A carry-in route should be suitably planned from the main street to the MO bldg.

After interior planning had almost been decided with consideration of the above seven requirements, the following two site plans were proposed in the 
architectural-design stage:

- A-type (Fig. 9a): The shape of every floor is planned to be rectangular because the efficiency of interior utilization and the construction cost are given the highest priority. The common parking area is set to include 14 parking lots. The city hall building is set on the center of the site to connect with the MO bldg. Since the first to sixth floors are designed to have sufficient total floor area between them, the seventh floor is set to have setbacks on the east and west sides, and the total floor area is set at $18,000 \mathrm{~m}^{2}$. A large eave covering the main entrance and the porch is planned for outdoor activities. A pedestrian walkway connecting city hall and the MO bldg. is set on the second floor;

- B-type (Fig. 9b): The common parking area is planned to have as many parking lots as possible (29 lots). The common parking area is expected to be used by not only city hall visitors, but also by visitors to the whole urban-core area, including the MO bldg. and Kitami station. The total floor area of the B-type design is set to $18,000 \mathrm{~m}^{2}$. An eave covering the main entrance and the porch is planned for outdoor activities. A pedestrian walkway connecting city hall with the MO bldg. is set on the second floor.

\subsection{Environmental Issues}

During planning, the connection between the new city hall and the MO bldg. was one of the most important issues. In planning the site of the city hall, it is desirable to reduce the negative impact of snow to create outdoor comfort and reduce problems in winter. Specifically, the environmental issues need to be addressed by proper planning, including reduction in the sizes of the snowdrifts in Areas A-D, and easing the burden of snow-removal from Area $E$ at the following locations:

(A) around the main entrance (including the porch);

(B) common parking area;

(C) sidewalks of the main street;

(D) sub entrance;

(E) parking area.

In the two proposed site plans (A-type and B-type), the impacts of snow upon the above five areas were assessed with snow simulations using the wind tunnel.

\section{Results of the Snow Simulations}

Figs. 10 and 11 show the results of the snow simulations for the A-type and the B-type designs. The results were analyzed in terms of the five environmental considerations listed in Section 4.2.
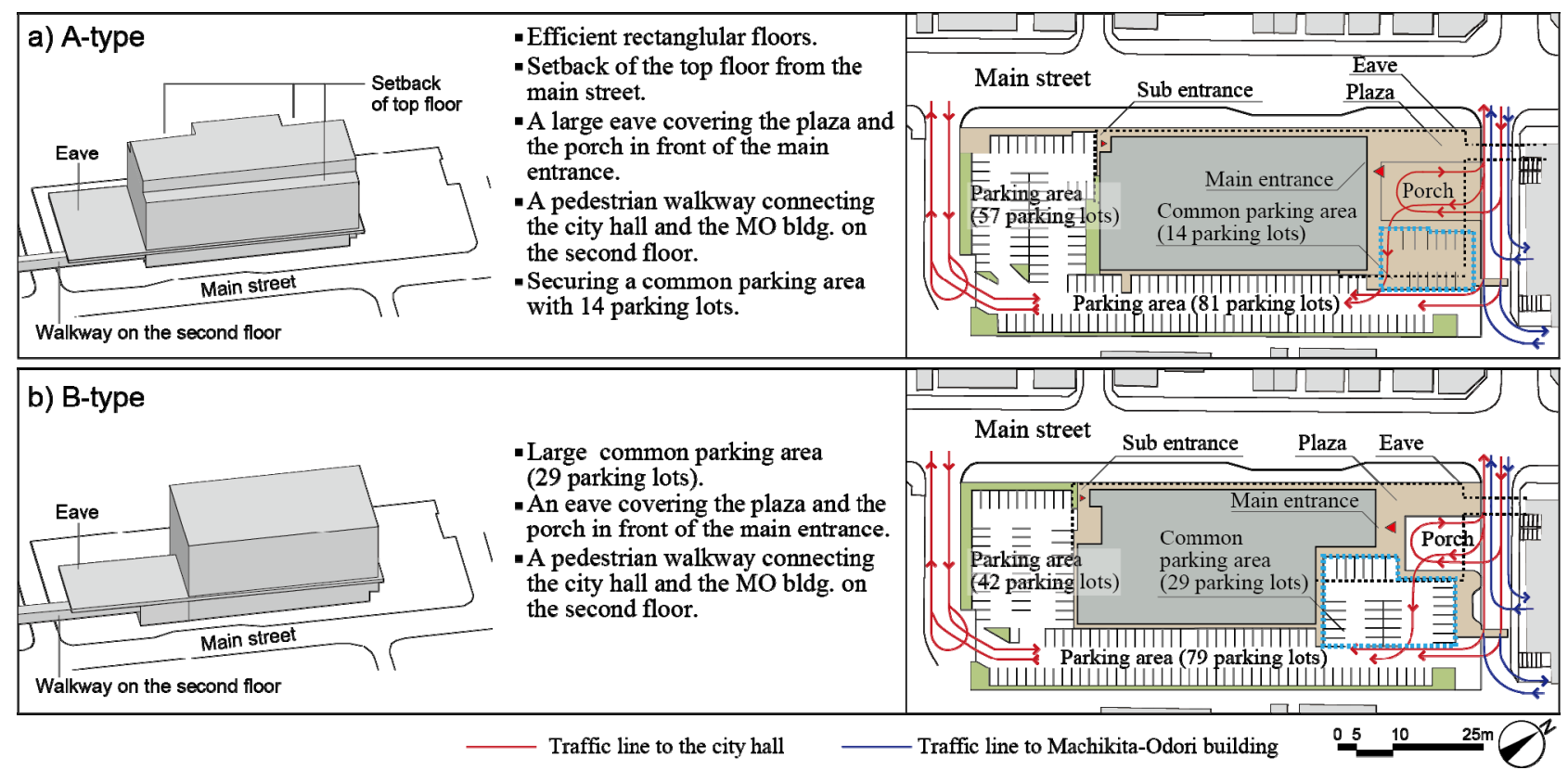

Fig. 9 Proposed site plans of Kitami city hall. 


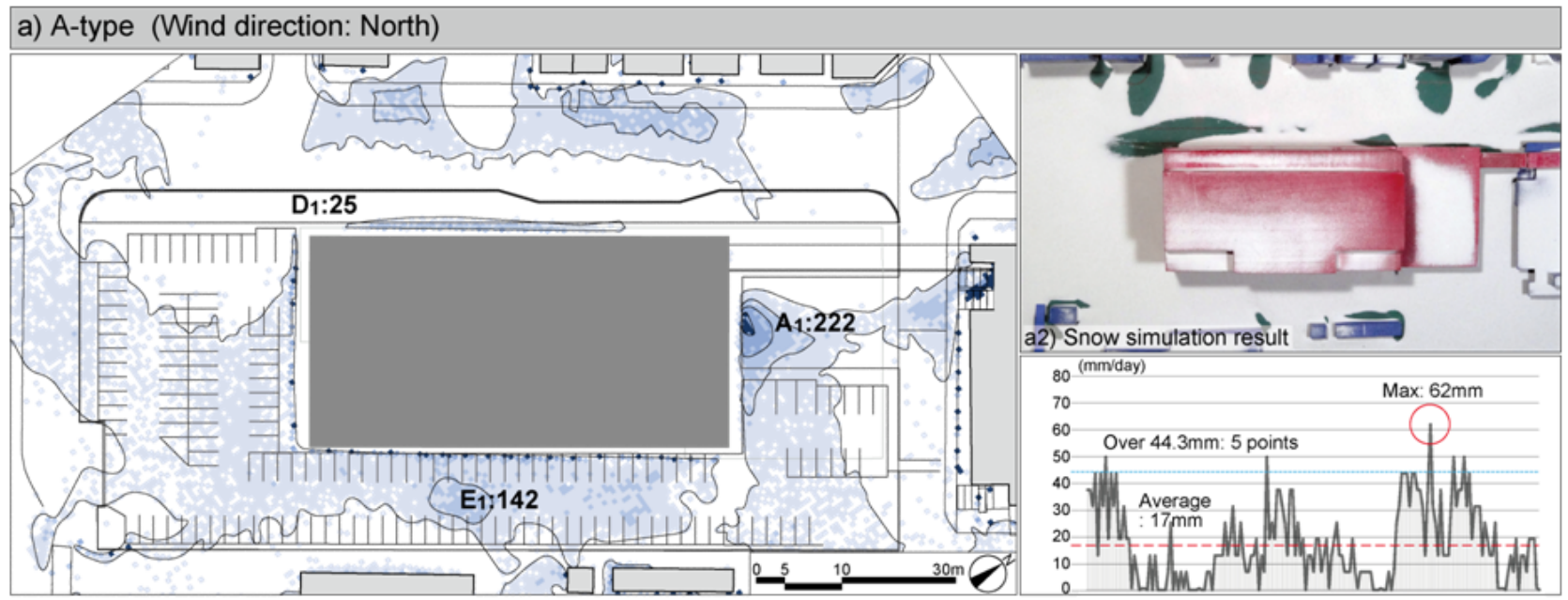

a1) Snow depth $\square 0 \mathrm{~mm} \square 50 \mathrm{~mm} \square 100 \mathrm{~mm} \square 150 \mathrm{~mm} \square 200 \mathrm{~mm} \square 250 \mathrm{~mm} \square 300 \mathrm{~mm}$

a3) Snow depth on the sidewalk along the main street ( $\mathrm{mm} /$ day)

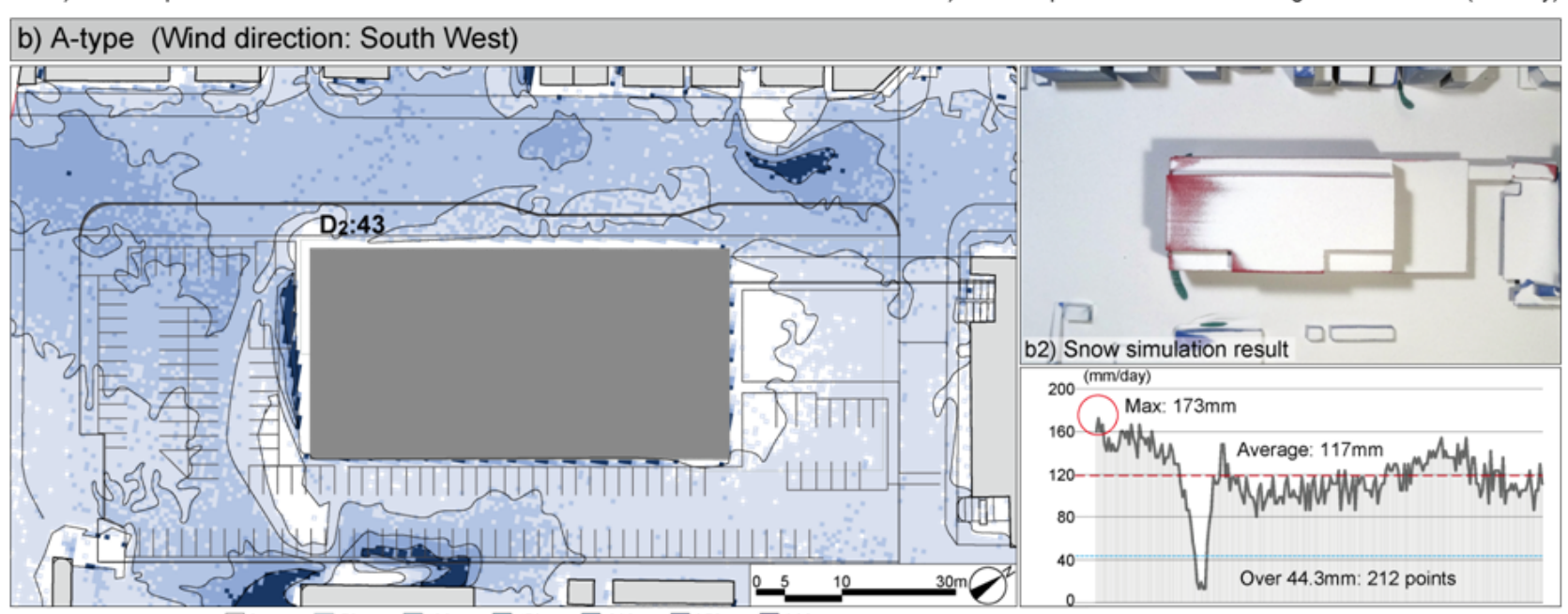

b1) Snow depth $\square 0 \mathrm{~mm} \square 50 \mathrm{~mm} \square 100 \mathrm{~mm} \square 150 \mathrm{~mm} \square 200 \mathrm{~mm} \square 250 \mathrm{~mm} \square 300 \mathrm{~mm}$

b3) Snow depth on the sidewalk along the main street ( $\mathrm{mm} /$ day).

Fig. 10 Snow-simulation results for the A-type design.

\subsection{Common Snow-Environment Problems between} the A-Type and B-Type Designs

Comparing the results of snow simulations for the A-type and B-type designs, common snow environmental-problems were observed in terms of environmental considerations A, B, D, and E:

(A) Around the main entrance: When the wind blew in the northward direction, snowdrifts were formed around the main entrances under the eaves (Point $A_{1}$, $A_{2}$ and $A_{3}$ ). Since the prevailing winds impinged the walls of the main entrances at 125 degrees and blew back, the snow drifted there. In addition, the eaves prevented the drifting snow from being blown leeward. When the wind direction was southwest, snow did not drift around the main entrances because the main entrances were shielded from the winds. There was not much difference in terms of the amount and average depth of snow around the main entrance between the A-type and B-type designs (Table 2);

(B) Common parking area: When the wind direction was north, large snowdrifts did not form in the common parking areas in either of the two plans. The average snow depths were $5.1 \mathrm{~cm}$ in the A-type design and $4.8 \mathrm{~cm}$ in the B-type. There were no differences in the average snow depths between the two plans. When the wind direction was southwest, large snowdrifts did not form either. The average snow depths were $5.9 \mathrm{~cm}$ in the A-type design and $6.5 \mathrm{~cm}$ in the B-type. There were no large differences between the two plans (Table 2); 
a) B-type (Wind direction: North)

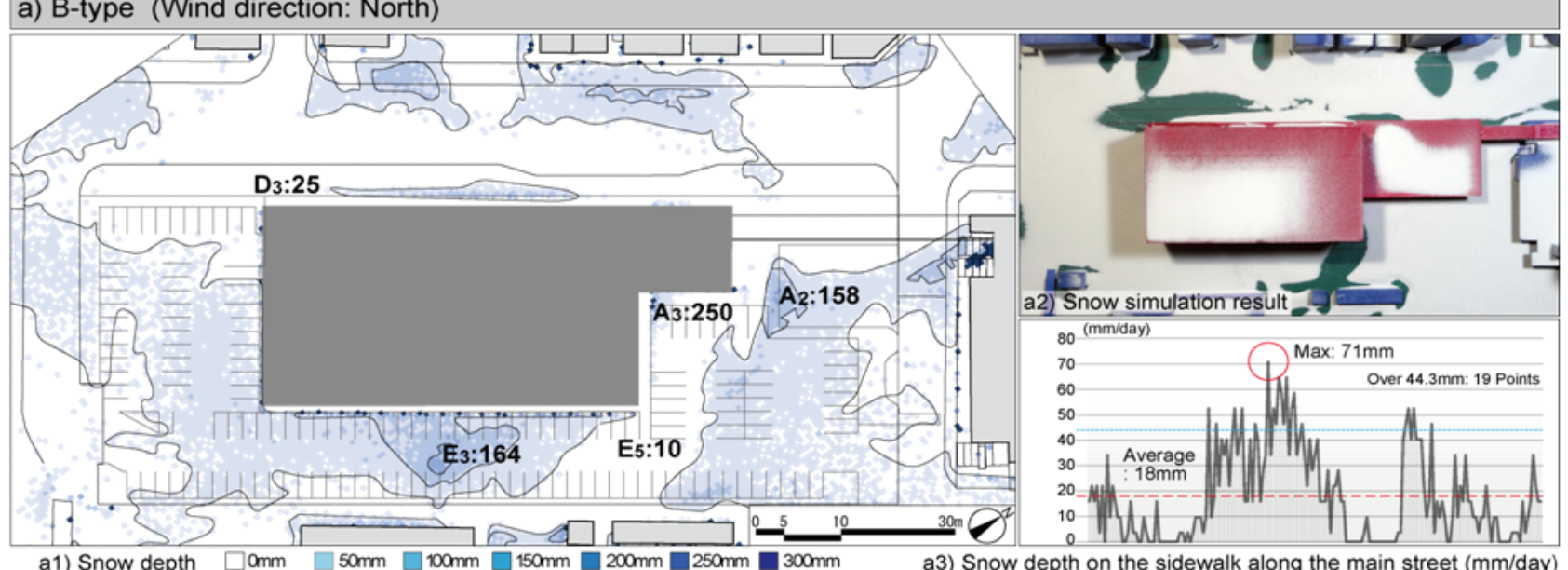

a1) Snow depth $\square \mathrm{omm} \square 50 \mathrm{~mm} \square 100 \mathrm{~mm} \square 150 \mathrm{~mm} \square 200 \mathrm{~mm} \square 250 \mathrm{~mm} \square 300 \mathrm{~mm}$

a3) Snow depth on the sidewalk along the main street ( $\mathrm{mm} / \mathrm{day})$

b) B-type (Wind direction: North)

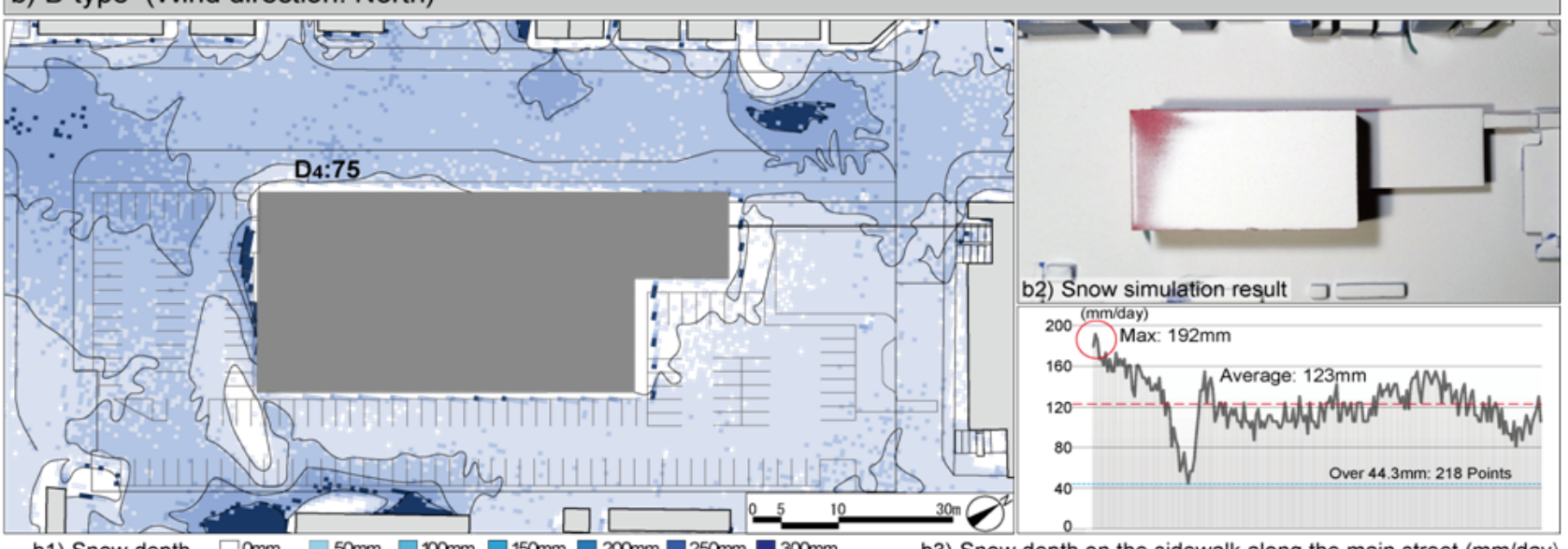

b1) Snow depth $\square 0 \mathrm{~mm} \square 50 \mathrm{~mm} \square 100 \mathrm{~mm} \square 150 \mathrm{~mm} \square 200 \mathrm{~mm} \square 250 \mathrm{~mm} \square 300 \mathrm{~mm}$

b3) Snow depth on the sidewalk along the main street ( $\mathrm{mm} /$ day).

Fig. 11 Snow simulation results for the B-type design.

Table 2 Snow-cover amount and average snow depth.

\begin{tabular}{|c|c|c|c|c|c|}
\hline \multirow{2}{*}{$\begin{array}{l}\text { Site plan } \\
\text { Wind direction }\end{array}$} & & \multicolumn{2}{|c|}{ A-type } & \multicolumn{2}{|c|}{ B-type } \\
\hline & & $\mathbf{N}$ & SW & $\mathbf{N}$ & SW \\
\hline Total snow amount on the entire site area & $\mathrm{m}^{3} /$ day & 268.6 & 497.6 & 256.0 & 503.2 \\
\hline Snow amount around the main entrance & $\mathrm{m}^{3} /$ day & 34.4 & 57.9 & 26.2 & 60.0 \\
\hline Average snow depth around the main entrance & $\mathrm{cm} /$ day & 4.1 & 7.0 & 3.6 & 8.2 \\
\hline Snow amount on the common parking area & $\mathrm{m}^{3} /$ day & 19.6 & 23.1 & 38.0 & 51.5 \\
\hline Average snow depth on the common parking area & $\mathrm{cm} /$ day & 5.1 & 5.9 & 4.8 & 6.5 \\
\hline \multicolumn{3}{|c|}{ Number of measurement points over $4.43 \mathrm{~cm} /$ day on the main street sidewalk 5} & 212 & 19 & 218 \\
\hline
\end{tabular}

(D) Sub entrance: When the wind direction was north, large snowdrifts were not observed around the sub entrances in either of the two plans. The maximum snow depths were $2.5 \mathrm{~cm}$ at Point $\mathrm{D}_{1}$ in the A-type design and $2.5 \mathrm{~cm}$ at Point $\mathrm{D}_{3}$ in the B-type. When the wind direction was southwest, large snowdrifts were not observed either. The maximum snow depths were $4.3 \mathrm{~cm}$ at Point $\mathrm{D}_{2}$ in the A-type design and $7.5 \mathrm{~cm}$ at Point $\mathrm{D}_{4}$ in the B-type. Since wind-corner effects can increase the wind velocity, the snow covering around the sub entrances was blown away and the snowdrifts decreased there;

(E) Parking area: When the wind direction was north, the total amount of snow covering the entire site area was $268.6 \mathrm{~m}^{3} /$ day for the A-type design and $256.0 \mathrm{~m}^{3} /$ day for the B-type. When the wind direction 
was southwest, the total snow amounts were $497.9 \mathrm{~m}^{3} /$ day for the A-type design and $503.2 \mathrm{~m}^{3} /$ day for the B-type. There were no large differences between the two plans under either wind direction (Table 2).

\subsection{Different Problems with the Snow Environment for the A- and B-Type Designs}

(A) Around the main entrance: When the wind direction was north, snowdrifts were formed around the main entrances in the two plans, but the shapes of snowdrifts differed. In the A-type design, there was one large snowdrift around the main entrance. The snow depth was $22.2 \mathrm{~cm}$ at Point $\mathrm{A}_{1}$, which would cause problems for pedestrians. In the B-type design, there were two kinds of snowdrifts on the side of the main entrance (Point $\mathrm{A}_{2}$ ) and on the internal-corner area (Point $\mathrm{A}_{3}$ ). The snow depth was $15.8 \mathrm{~cm}$ at Point $\mathrm{A}_{2}$ and $25.0 \mathrm{~cm}$ at Point $\mathrm{A}_{3}$, potentially causing problems for pedestrians. The size of the snowdrifts near the main entrance in the A-type design was larger than that in the B-type. This was because the length of the wall facing the prevailing wind in the A-type design was longer than that in the B-type $(37.0 \mathrm{~m}$ versus $26.6 \mathrm{~m}$ ), allowing it to catch more snowdrifts. On the other hand, the snowdrift in the internal-corner area in the B-type design was very large, because the wind increased by the external corner blew the snow leeward, causing it to drift into the internal-corner area;

(C) Sidewalks of the main street: The snow covering on the main street sidewalks of the B-type design was deeper than that in the A-type in the north and southwest wind directions. When the wind direction was north, the maximum snow depth was $6.2 \mathrm{~cm}$ and the average snow depth was $1.7 \mathrm{~cm}$ in the A-type design, whereas these quantities were respectively $7.1 \mathrm{~cm}$ and $1.8 \mathrm{~cm}$ in the B-type. When the wind direction was southwest, the maximum snow depth was $17.3 \mathrm{~cm}$, and the average snow depth was $1.8 \mathrm{~cm}$ in the A-type design, and these quantities were respectively $19.2 \mathrm{~cm}$ and $1.8 \mathrm{~cm}$ in the B-type. In Kitami, the average natural snow melt over the last five years (Dec. 2010 to Mar. 2015) has been $4.43 \mathrm{~cm} /$ day. Snow depth over the average natural snow melt remained on the sidewalks, causing inconvenience for pedestrians. When the wind direction was north, there were 5 measurement points with snow depths over $4.43 \mathrm{~cm}$ in the A-type design and 19 points in the B-type. When the wind direction was southwest, there were 212 points over $4.43 \mathrm{~cm}$ in the A-type design and 218 points in the B-type (Table 2). Hence, it was found that the local snowdrifts were easily formed on the sidewalks in the B-type design. Because the wall length along the sidewalk in the B-type design was longer than that in the A-type design ( $82.6 \mathrm{~m}$ versus $73.6 \mathrm{~m}$ ), the longer wall increased the amount of snow blown to the ground and the turbulence of the snow cover. This difference would strongly affect outdoor activities, because the sidewalk of the main street is a highly important path connecting the city hall to the MO bldg.;

(E) Parking area: When the wind direction was north, the shapes of the snowdrifts in the parking areas beside the railroad were different between the A-type and B-type designs. The snow depth was $14.2 \mathrm{~cm}$ at Point $\mathrm{E}_{1}$ in the former and $16.4 \mathrm{~cm}$ at Point $\mathrm{E}_{2}$ in the latter; the snow depth in the B-type was deeper and the turbulence of the snow cover was larger than in the A-type design. The total amounts of snow covering the entire site area were almost same (Section 5.1), but the larger turbulence of the snow cover in the B-type design caused the snow to remain more easily and tended to cause problems with snow removal. The top floor's setback in the A-type design decreased the wind velocity blowing to the ground, thereby causing less turbulence of the snow covering in the parking area. In addition, the greater number of corners of the B-type building caused leeward turbulence of the snow cover. 
6. Reflection of the Environmental-

\section{Assessment Results of Architectural Planning}

The results of the environmental assessments clarified by the snow simulations are presented in Table 3 for reflection in architectural planning:

(1) Showing the A-type's superiority based on the environmental assessment and reflecting the results in the site planning: The environmental-assessment results showed that the A-type design is superior in terms of the snow environment to the B-type. The A-type design can reduce the local snowdrifts on the main street sidewalk in north and southwest wind directions. In addition, this design can relieve the burden of the snow removal because the turbulence of the snow covering in the parking area was decreased under the north wind direction.

Based on the results of environmental assessment and studying the plan for the interior, the A-type design was selected;

(2) Showing the problems of the A-type by environmental assessment and reflecting the results in architectural planning: The environmental assessment showed that the snowdrifts that can cause problems for pedestrians tend to be formed around the main entrance. In architectural planning, the eave was reduced in size and the road-heating system was set on the walkway under the eave against the snowdrifts. The design plan reflecting the environmentalassessment results is shown in Fig. 12.

Table 3 Environmental assessments for the two site plans.

\begin{tabular}{|c|c|c|c|c|}
\hline \multirow[b]{2}{*}{ Wind Direction } & \multicolumn{2}{|l|}{ A-type } & \multicolumn{2}{|l|}{ B-type } \\
\hline & North & Southwest & North & Southwest \\
\hline $\begin{array}{l}\text { (A) Around the main } \\
\text { entrance }\end{array}$ & $\begin{array}{l}\text { A large snowdrift were } \\
\text { formed. }\end{array}$ & $\begin{array}{l}\text { Large snowdrifts were not } \\
\text { formed. }\end{array}$ & $\begin{array}{l}\text { Two snowdrifts were } \\
\text { formed. }\end{array}$ & $\begin{array}{l}\text { Large snowdrifts were not } \\
\text { formed. }\end{array}$ \\
\hline $\begin{array}{l}\text { (B) Common parking } \\
\text { area }\end{array}$ & \multicolumn{4}{|c|}{$\begin{array}{l}\text { Large snowdrifts were not formed. } \\
\text { There was no difference of the average snow depth. }\end{array}$} \\
\hline $\begin{array}{l}\text { (C) Sidewalks of the } \\
\text { main street }\end{array}$ & \multicolumn{2}{|c|}{ The local snowdrifts were decreased. } & \multicolumn{2}{|c|}{ The local snowdrifts were increased. } \\
\hline (D) Sub entrance & \multicolumn{4}{|c|}{ Large snowdrifts were not formed. } \\
\hline $\begin{array}{l}\text { (E) Burden of } \\
\text { removing snow on the } \\
\text { entire site area }\end{array}$ & $\begin{array}{l}\text { The turbulence of snow } \\
\text { covering on the parking } \\
\text { area was decreased. }\end{array}$ & $\begin{array}{l}\text { There was no difference } \\
\text { of the total snow amount. }\end{array}$ & $\begin{array}{l}\text { The turbulence of snow } \\
\text { covering on the parking } \\
\text { area was increased. }\end{array}$ & $\begin{array}{l}\text { There was no difference } \\
\text { of the total snow amount. }\end{array}$ \\
\hline
\end{tabular}

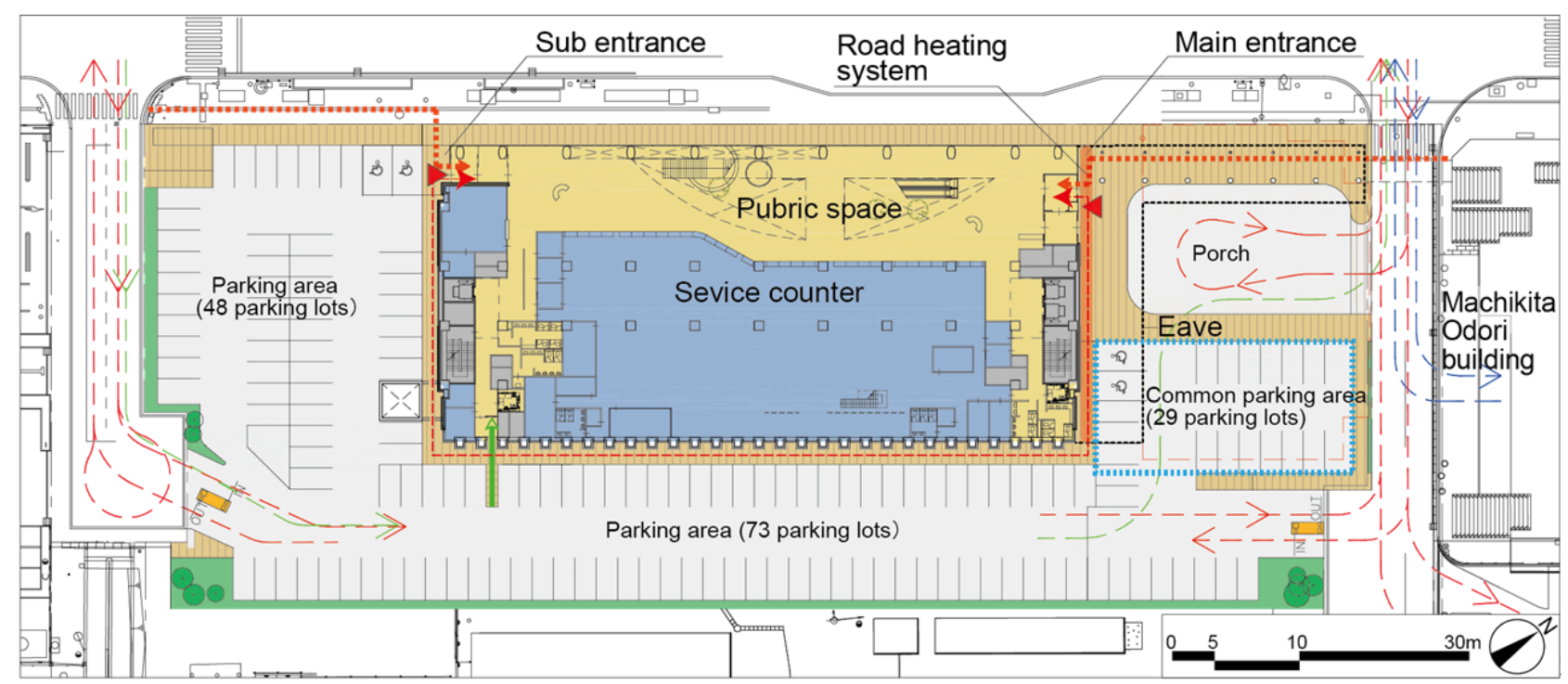

Fig. 12 The design plan of the new city hall. 


\section{Conclusions}

In this study, the two site plans proposed for the Kitami city hall-renewal project (A-type and B-type) were environmentally assessed through snow simulations using a wind tunnel. The results of the assessments were reflected in the architectural planning. The process of the architectural planning and the assessments in this study are shown in Fig. 13.

Two site plans (A-type and B-type) were proposed with consideration of the interior utilization and the common parking area based on the specified conditions.

The snow environments of the two site plans were tested by snow simulations in a wind tunnel, and three of the features of the snow environment were clarified as follows:

(1) In the two site plans, large snowdrifts were formed around the main entrance, causing problems for visitors to the city hall. The snowdrifts were encouraged by the large eaves covering the main entrances;

(2) There were no large differences in the snow situations of the common parking areas and the sub entrances between the two site plans. The differences in the site plan did not significantly affect the snow environments;

(3) Comparing the two site plans, the A-type design could reduce the local snowdrifts on the main street sidewalk when the wind direction was to the north or to the southwest. This plan can also reduce the snowdrifts in the parking area beside the railroad when the wind direction was to the north.

According to the assessment results, the A-type design was found to be superior in terms of the snow environment to the B-type ("Result 1" in Fig.13).

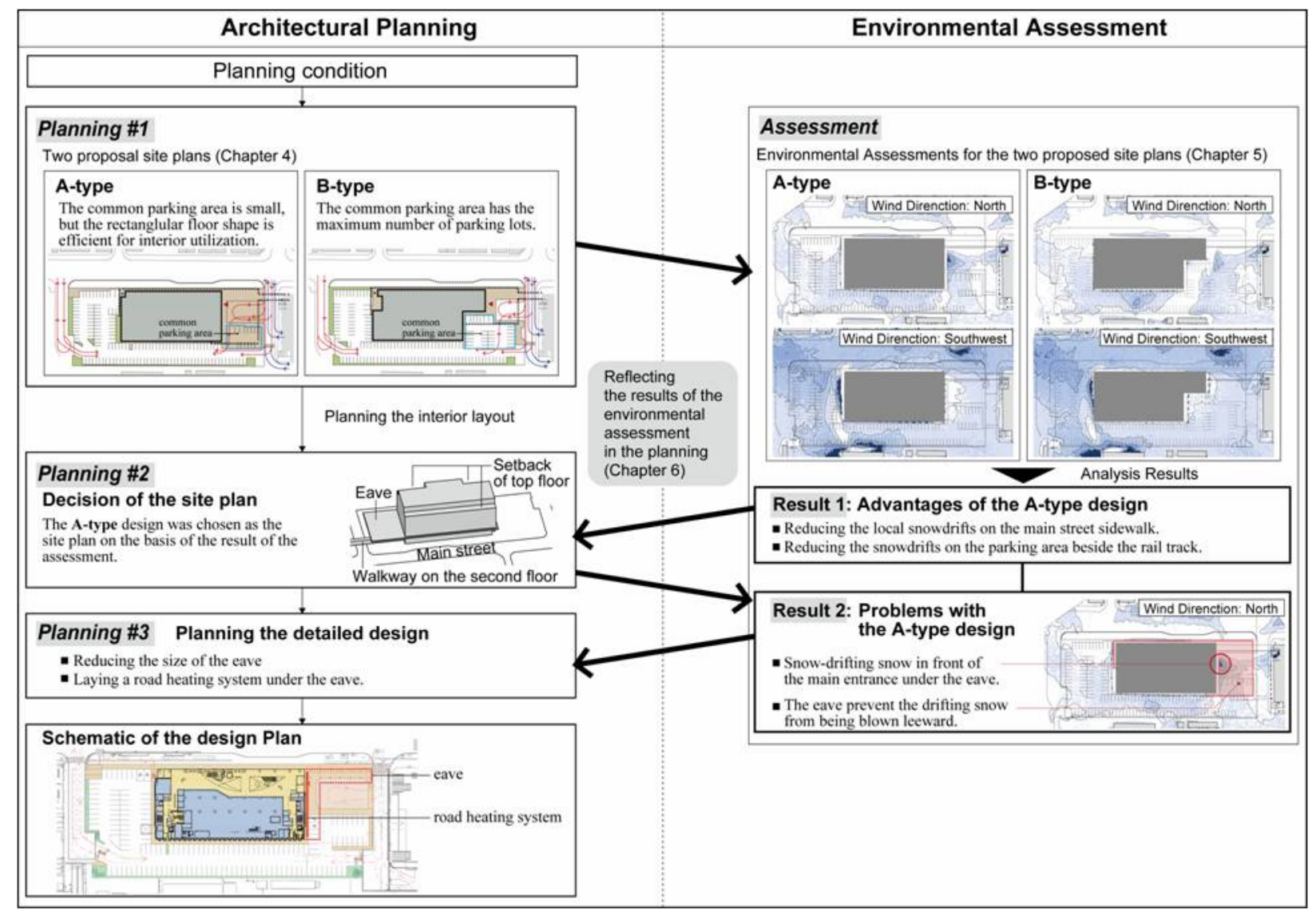

Fig. 13 The planning process incorporating environmental assessments. 
The A-type design was chosen as the site plan for the new Kitami city hall by reference to Result 1 .

When the assessment results were analyzed again for the A-type design, it was found to have a large snowdrift problem around the main entrance caused by the large eave ("Result 2" in Fig.13).

Based on Result 2, the eave that would cause snow drift around the main entrance was reduced in size and a road-heating system was set on the walkway under the eave to help melt the snowdrift.

Assessing the snow environment in parallel with architectural planning could help to show the reason for deciding a desirable site plan and taking suitable countermeasures against snowdrifts around the main entrance during architectural planning. It is concluded that this design process with environmental assessment can offer desirable city hall planning to reduce the impact of snow. This planning process has a high degree of viability for winter cities. Future related research should consider more building shapes in other winter cities to clarify the relation between planning and the environment based on this process.

\section{Acknowledgments}

This work was supported by JSPS KAKENHI Grant Number 25249082.

\section{References}

[1] Pressman, N. 1995. Northern Cityscape: Linking Design to Climate. Yellowknife: Winter Cities Association.

[2] Ebrahimabadi, S., Nilsson, K. L., and Johansson, C. 2015. "The Problems of Addressing Microclimate Factors in Urban Planning of the Subarctic Regions." Environment and Planning B: Planning and Design 42 (3): 415-30.

[3] Ng, E. 2009. "Policies and Technical Guidelines for Urban Planning of High-Density Cities-Air Ventilation Assessment (AVA) of Hong Kong." Building and Environment 44 (7): 1478-88.

[4] Bosselmann, P., Flores, J., Gray, W., Priestley, T., Anderson, R., Arens, E., and Kim, J. J. 1984. Sun, Wind, and Comfort: A Study of Open Spaces and Sidewalks in Four Downtown Areas. Berkeley, CA: Center for Environmental Design, University of California.
[5] Arens, E., and Bosselmann, P. 1989. "Wind, Sun and Temperature-Predicting The Thermal Comfort Of People In Outdoor Spaces." Building and Environment 24 (4): 315-20.

[6] Kim, H., and Macdonald, E. 2015. "Wind and the City: An Evaluation of San Francisco's Planning Approach Since 1985." Environment and Planning B: Planning and Design: 0265813515607474.

[7] Yukawa, T., Tsutsumi, T., Taniguchi, N., and Tomabechi, T. 2012. "Snow Accumulation on Residential Area in Snowy Cold Region." AIJ J. Technol. Des. 18 (40): 1013-7.

[8] Setoguchi, T. 2004. "Efficiencies of Infill Developments against Snow Problem in Winter Cities-The Snow Simulations for Desirable Block Designs Using Wind Tunnel." JAABE 3 (2): 335-40.

[9] Setoguchi, T., and Tsutsumi, T. 2006. "Urban Design Guidelines for the Urban Complex Redevelopment Project Provided from Environmental Assessments with Snow and Wind Simulations: The New Urban Design Approaches with Snow and Wind Environmental Assessments for Snow and Cold Regions." J. Archit. Plann. AIJ 604: 131-8.

[10] Setoguchi, T., and Tsutsumi, T. 2007. "Snow and Wind Environmental Assessment on the Public Space Comparing High-Rise and Medium-Rise Building Blocks Using the Wind Tunnel Simulation." J. Archit. Plann., AIJ 614: 167-74.

[11] Setoguchi, T., and Tsutsumi, T. 2007. "The Comparison of Snow and Wind Impacts between High-Rise and Medium-Rise Building Blocks Using the Wind Tunnel Simulation for Snow and Cold Cities." J. Archit. Plann. AIJ 619: 101-8.

[12] Setoguchi, T. 2008. "New Urban Design Approaches with Snow Simulations for Cold And Snowy Cities." JAABE 7 (1): 93-9.

[13] Setoguchi, T. 2009. "The Development of Urban Design Planning Process Linking with Snow and Wind Environmental Assessments on the Urban Complex Redevelopment Project in Snowy and Cold Cities." $J$. Archit. Plann. AIJ 642: 1777-86.

[14] Setoguchi, T., Satoh, K., Watanabe, N., and Tsutsumi, T. 2012. "The Urban Design Assessments for the Relationship between Urban Envelope and Snow Remove Energy Using Snow and Wind Simulations in Snowy And Cold Cities." J. Archit. Plann. AIJ 682: 2789-98.

[15] Watanabe, N., Setoguchi, T., Sato, K., and Tsutsumi, T. 2016. "New City Block Design Approaches Incorporating Environmental Assessment for Downtown Districts in Cities with Severe Winter Climates." JAABE 15 (3): 455-62. 
[16] Anno, Y. 1984. "Requirements for Modeling of a Snowdrift." Cold Regions Science and Technology 8 (3): 241-52.

[17] Oikawa, S., Tomabechi, T., and Ishihara, T. 2007. "Study of Wind Tunnel Similarity on Snowdrift around Buildings." J. Snow Eng. of Japan 23 (2): 13-32.

[18] Tsuchiya, M., Tomabechi, T., Hongo, T., and Ueda, H.
2002. "Characteristics of Wind Flow Acting on Snowdrift on a Stepped Flat Roof." J. Struct. Constr. Eng., AIJ (555): 53-9.

[19] Emori, I., Saito K., and Sekimoto K. 2000. Mokeijikken no Riron to Ouyou (Theory and Application of Model Experiments). 3rd ed. Tokyo: Hakuhodo. (in Japanese) 